\title{
Characterizing the Mechanism of Biological Control of Postharvest Diseases on Fruits with a Simple Method to Study Competition for Nutrients
}

\author{
W. J. Janisiewicz, T. J. Tworkoski, and C. Sharer \\ U.S. Department of Agriculture, Agricultural Research Service, Appalachian Fruit Research Station, 45 Wiltshire Road, Kearneysville, WV \\ 25430. \\ Accepted for publication 31 July 2000.
}

\begin{abstract}
Janisiewicz, W. J., Tworkoski, T. J., and Sharer, C. 2000. Characterizing the mechanism of biological control of postharvest diseases on fruits with a simple method to study competition for nutrients. Phytopathology 90:1196-1200.

Biocontrol agents may compete with pathogens for nutrients and space to delay or prevent decay of fruits after harvest. These mechanisms of biological control have been difficult to study because no method has been available to determine the significance of each of the components of competition. We developed a nondestructive method using tissue culture plates with cylinder inserts containing defusing membrane at one end to study competition for nutrients without competition for space. Other biocontrol mechanisms in which direct contact between an antagonist and a pathogen is not required also can be studied. The method was used to determine the competition between the yeastlike biocontrol agent, Aureo-
\end{abstract}

ABSTRACT

The mechanisms of biological control of plant pathogens by antagonistic bacteria and fungi have been a subject of many studies in the past 2 decades. Most of these studies dealt with antagonists controlling soilborne and, to a lesser extent, foliar pathogens. Mechanisms of biological control included antibiosis, parasitism, induced resistance, and competition for space and limited resources. Less work has been reported in the area of biological control of postharvest diseases of fruits (2-8,10,12,21,23-25). Postharvest biological control of fruit is unique in that antagonists are applied directly to wounds, i.e., the point of entry for the pathogens, and the wound site are often rich in nutrients (19). Most postharvest fruit pathogens are necrotrophs, which require nutrients for germination and initiation of the pathogenic process. Therefore, competition for nutrients and space can be an effective mechanism of biological control. Several possible biocontrol mechanisms have been suggested to operate on fruit $(2-8,16,20-$ 25) including antibiosis, parasitism, induced resistance, and competition for nutrients and space. In no case however, was the mechanism of biological control by an antagonist fully explained. Competition for nutrients and space has often been implied but direct proof of the importance of this mechanism in the fruit system is still lacking $(2,3,5-7,16,20,22-25)$. This is due mainly to the lack of appropriate methods to study this type of interaction. Especially challenging has been the separation of competition for nutrients from competition for space.

Corresponding author: W. Janisiewicz; E-mail address: wjanisie@afrs.srs.usda.gov

Publication no. P-2000-0823-01R

This article is in the public domain and not copyrightable. It may be freely reprinted with customary crediting of the source. The American Phytopathological Society, 2000. basidium pullulans, and Penicillium expansum for limited nutrients in apple juice during $24 \mathrm{~h}$ incubation, simulating a fruit wound. The antagonist depleted amino acids and inhibited germination of $P$. expansum conidia. Exposing these conidia to fresh apple juice increased conidial germination to the level comparable to that exhibited by conidia which were not exposed to the antagonist. Because the culture plate method was nondestructive, follow-up experiments in an agar diffusion test were conducted. Juice in which the antagonist grew did not inhibit germination of $P$. expansum conidia that were seeded on the plates. This corroborates findings from the culture plate method that inhibition of the conidia germination resulted from competition for nutrients. The new method can be coupled with existing techniques to improve understanding of antagonist-pathogen interaction for biological control of postharvest diseases.

Additional keywords: blue mold, microbial interaction.
In the isolates from fruit, we found many yeasts and a few bacteria that effectively controlled blue mold on pome fruits $(7,11,13$, $14,16,17)$. Most do not produce any inhibitory substances during in vitro testing and are very efficient in utilizing carbon and nitrogen sources in apple and pear wounds. Competition for nutrients and space are likely mechanisms of biological control that require further investigation. Methods to study these mechanisms are limited in scope. Competition for nutrients and competition for space are often considered together for a given antagonist without ascribing the proper level of significance to each mechanism.

In this paper, we described a simple approach with an in vitro system closely resembling in vivo conditions to study competition for nutrients as the mechanism of biological control of fruit decays. We used one of our antagonists, a yeastlike Aureobasidium pullulans (de Bary) Arnold (isolate ST1-A24), that is effective against blue mold of pome fruits to demonstrate the usefulness of this in vitro method.

\section{MATERIALS AND METHODS}

Pathogen. Penicillium expansum Link culture was grown on potato dextrose agar (PDA). The PDA medium was made from the extract of $200 \mathrm{~g}$ of boiled potatoes, $20 \mathrm{~g}$ of dextrose, and $15 \mathrm{~g}$ of agar per liter (Difco Laboratories, Detroit). The fungus was originally isolated from a decayed apple and has been one of the most aggressive isolates in our collection. It has been used extensively as the pathogen in various biocontrol tests including the pilot test with the BioSave ${ }^{\mathrm{TM}}$ product $(15,16)$. Conidia were collected from 7- to 10-day old cultures and adjusted to a concentration of $2 \times 10^{5}$ or $1 \times 10^{6}$ conidia per $\mathrm{ml}$ with a hemacytometer as described previously (16). 
Antagonist. The yeastlike antagonist isolate ST1-A24 was isolated from 'Golden Delicious' apple fruit in a 7-year-old unmanaged orchard planted to 'Golden Delicious', 'Red Delicious', 'Empire', 'Stayman', and 'York' apple trees at the Appalachian Fruit Research Station in Kearneysville, West Virginia according to the procedure described previously (11). It was effective in controlling blue mold of apple caused by $P$. expansum (W. J. Janisiewicz and C. Sharer, unpublished data). The isolate was identified by Centraalbureau Voor Schimmelcultures, Delft, the Netherlands as A. pullulans (de Bary) Arnold. For the antagonistpathogen interaction tests, the antagonist was grown in $250-\mathrm{ml}$ Erlenmeyer flasks with $50 \mathrm{ml}$ of nutrient yeast dextrose broth (NYDB; Difco) on a shaker at $150 \mathrm{rpm}$ for $20 \mathrm{~h}$. The NYDB contained $8.0 \mathrm{~g}$ of nutrient broth, $5.0 \mathrm{~g}$ of yeast extract, and $10 \mathrm{~g}$ of dextrose per liter. The culture was harvested by centrifugation at $6,500 \times g$, washed two times in steriłe-distilled water (SDW), and resuspended in SDW, and the concentration was adjusted to an optical density of 0.13 (75\% transmittance or $\left.8.7 \times 10^{6} \mathrm{CFU} / \mathrm{ml}\right)$ at $420 \mathrm{~nm}$ (Spectronic21DUV; Milton Roy Co., Rochester, NY). For the biocontrol tests on fruit, the antagonist was prepared as described above, except washing in SDW was not conducted.

Nutritional profile of the antagonist. The ability of the isolate ST1-A24 to utilize major carbon sources in apple juice was first determined in YT plates (Biolog Inc., Hayward, CA) as described earlier (11) using the MicroLog-3N program (Biolog). Additional tests for the utilization of the major carbon sources in apple juice were conducted in a minimum salt medium for yeast as described in Barnett et al. (1) with fructose, sucrose, glucose, or sorbitol as a single carbon source at $3.5 \mathrm{~g} /$ liter. Isolate ST1-A24 utilized each of the tested sugars. Sucrose was utilized most quickly, followed by glucose, sorbitol, and fructose. Isolate ST1-A24 utilized aspartic acid, glutamic acid, and serine equally well in the minimum salt medium with glucose as the carbon source and $0.5 \mathrm{M}$ amino acids.

Biocontrol test on apple. The antagonist ST1-A24 was first evaluated for biocontrol potential against blue mold on 'Golden Delicious' apple according to primary and secondary screening procedures described previously $(9,16)$. In the following test, the fruit were wounded with 16 penny nails, two wounds per fruit 2-cm apart, along the stem calyx axis. The wounds were inoculated with $25 \mu \mathrm{l}$ of the mixture of antagonist cells at $8.7 \times$ $10^{6} \mathrm{CFU} / \mathrm{ml}$ and the $P$. expansum conidia at $2 \times 10^{5}$ conidia per $\mathrm{ml}$ and incubated on fruit trays in plastic boxes at $24^{\circ} \mathrm{C}$ for 7 days before evaluation for severity and incidence of infection as described previously (16). Fruits inoculated with the pathogen alone served as the control. There were six fruits per replicate, and three replicates per treatment. In a similar large scale test, the fruit were treated as above, except after treatment the apples were placed in cardboard boxes with polyethylene liners on fruit trays and stored at $1^{\circ} \mathrm{C}$ for 3 months. There were 20 fruit per replicate, and five replicates per treatment. The treatments were arranged in complete randomized blocks. Biocontrol potential of this antagonist was confirmed in several similar tests with different number of fruits and various concentrations of the antagonist.

Competition experiments in culture plates with cylinder inserts. To test the effect of nutrient depletion by an antagonist on germination and growth of $P$. expansum conidia, tissue culture plates with 24 wells per plate (Costar, Corning Inc., Corning, NY) and culture plate inserts Millicell-CM (Millipore Corp., Bedford, MA) were used. The inserts consisted of a polystyrene cylinder and a hydrophilic polytetrafluoroethylene (PTFE) membrane (pore size $0.45 \mu \mathrm{m}$ ) attached to the bottom part of the cylinder (Fig. 1). The bottom part of the cylinder also has spacers which, after placing the cylinder in a culture well containing a liquid, allow for free liquid movement below the membrane. The movement of the liquid through the membrane was determined with a crystal violet solution that was put inside the cylinder insert while water was in the well outside the cylinder and vice versa. The movement of the dye through the membrane was observed within 3 min of placing the cylinder inside the well, irrespective of the placement of the dye solution. Inserts with the PTFE membrane were selected for this study because of the rapid movement of the liquid through this hydrophilic membrane and the ability to observe conidia and germlings on the membrane. Other membranes such as polycarbonate, polycarbonate polyvinylpyrrolidone-free, and mixed cellulose esters were either not as easily permeable at the same pore size as PTFE membranes or produced a background that was unsuitable for microscopic observation of the conidia and germlings.

Water and either 5 or $0.5 \%$ apple juice, alone or with the antagonist ST1-A24 $\left(4.35 \times 10^{6} \mathrm{CFU} / \mathrm{ml}\right)$ were dispensed in the wells of culture plates $(0.6 \mathrm{ml}$ per well). Suspensions containing an antagonist in apple juice were prepared by mixing $(1: 1$, $\mathrm{vol} / \mathrm{vol})$ apple juice at concentrations of 10 or $1 \%$ with a water suspension of the antagonist at $75 \%$ turbidity $\left(8.7 \times 10^{6} \mathrm{CFU} / \mathrm{ml}\right)$. This resulted in concentration of the antagonist similar to that used with commercial products. $P$. expansum conidial suspensions in water $\left(2 \times 10^{5}\right.$ conidia per $\left.\mathrm{ml}\right)$ were dispensed inside the cylinder inserts $(0.4 \mathrm{ml}$ per cylinder). Cylinders were placed in the wells and the plates were incubated at $26^{\circ} \mathrm{C}$ for $24 \mathrm{~h}$. The apple juice was prepared from fresh fruit, kept in a freezer in the laboratory, and was defrosted as needed. The concentration range of the apple juice used in this study included juice concentrations detected in drops of water recovered from apple wounds (19).

In developing this procedure, the plates with the cylinders were placed on an incubator shelf or on a rotary shaker at 50 rpm during incubation. There was no significant difference, however, between the conidia germination in shaken and unshaken plates for various antagonists. There was much less clumping of conidia or germlings in unshaken plates, which improved the quality of microscopic observations. Unshaken plates were used in subsequent studies. After incubation, cylinders were removed from the wells, the membrane was blotted from the bottom with tissue paper until all the liquid from the inside of the cylinder was absorbed. The membrane was cut with a sharp scalpel, transferred to a glass slide, stained with lactophenol-cotton blue, and mounted for microscopic observation.

After $24 \mathrm{~h}$ incubation and removal of the cylinders, antagonist populations in the wells were determined turbidimetrically with a spectrophotometer. Then the suspension was filtered through a

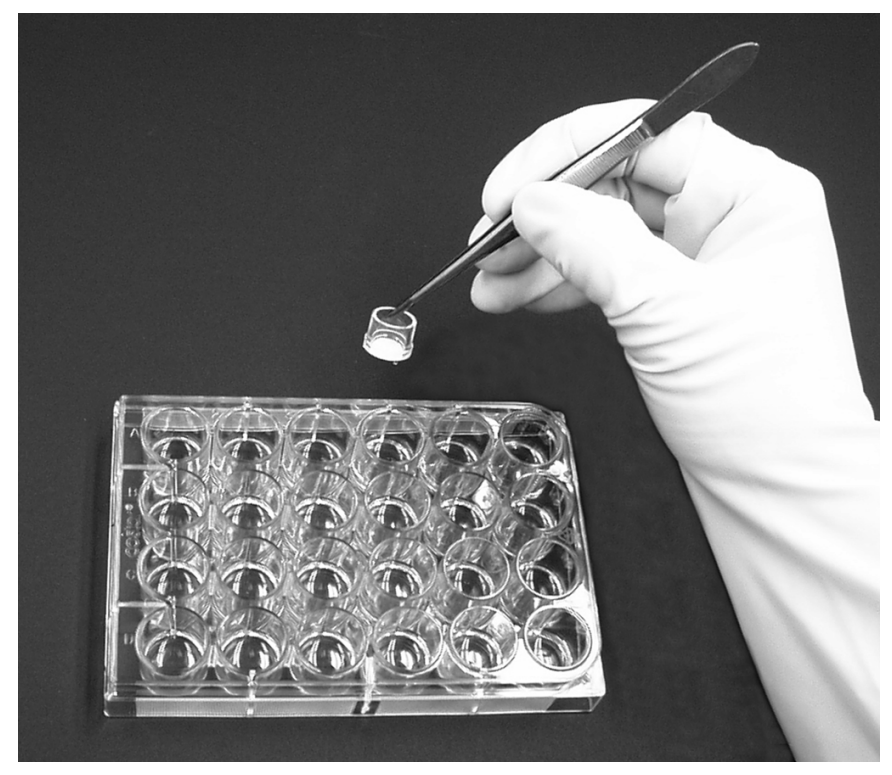

Fig. 1. Cylinder with membrane attached at bottom is inserted into a well of a tissue culture plate containing apple juice and the antagonist. Spacers on the cylinder bottom allow free movement of apple juice underneath to the membrane and diffusion of apple juice through the membrane into the cylinder. A suspension of the Penicillium expansum conidia is put inside the cylinder and kept separate from the yeast antagonist in the well. 
$0.22-\mu \mathrm{m}$ millipore filter and the filtrate was used to determine depletion of amino acids and production of antifungal compounds by the antagonist. The experiment was repeated.

Antibiosis tests on substrate from competition experiments. The filtrate was analyzed for depletion of major amino acids by the antagonist from the diluted apple juice during $24 \mathrm{~h}$ incubation. Three amino acids were detected with high-pressure liquid chromatography and fluorescence detection (Agilent Technologies, Wilmington, DE). In brief, the juice samples were derivatized with $o$-phthalaldehyde in mercaptopropionic acid and 9-fluorenylmethylchloroformate in acetonitrile with an automatic injector and separated on an amino acid column (Zorbax; Agilent Technologies). The amino acids were detected with a fluorescence detector (HP 1100; Agilent Technologies). The identity of the amino acids was confirmed by retention times with standards.

To determine viability of the conidia after $24 \mathrm{~h}$ exposure to the antagonist suspension, a parallel set of culture plates with the inserts was prepared as above. After $24 \mathrm{~h}$ incubation with the antagonist suspension, the inserts containing conidia were removed, the membranes blotted as above, and inserted into new wells containing only water or apple juice at concentrations corresponding to those inserted previously. After an additional $24 \mathrm{~h}$ incubation at $26^{\circ} \mathrm{C}$, the inserts were removed, the membranes were blotted, cut, and prepared for microscopic observation as described above.
The filtrate was evaluated for antifungal activity in an agar diffusion test. In this test, a plug (0.5-cm diameter) was removed from the center of petri dishes containing NYDA medium. The filtrate was dispensed into the holes $(100 \mu \mathrm{l}$ per hole), plates were incubated at $4^{\circ} \mathrm{C}$ for $24 \mathrm{~h}$, seeded with an aqueous suspension $(1 \times$ $10^{6}$ conidia per $\mathrm{ml}$ ) of $P$. expansum, incubated at $24^{\circ} \mathrm{C}$ for $48 \mathrm{~h}$, and evaluated for a zone of inhibition of fungal growth as described previously (18).

Antibiosis tests on agar plates. The agar diffusion test indicated that the antagonist did not produce compounds fungicidal to

TABLE 1. Percent germination of Penicillium expansum conidia on PTFE membranes in cylinders exposed for $24 \mathrm{~h}$ at $26^{\circ} \mathrm{C}$

\begin{tabular}{lrrrr}
\hline & \multicolumn{4}{c}{ Germination rating scale $^{\mathrm{a}}$} \\
\cline { 2 - 5 } Treatment & 1 & 2 & 3 & 4 \\
\hline Water & 96 & 4 & 0 & 0 \\
$0.5 \%$ juice & 7 & 12 & 48 & 33 \\
$5 \%$ juice & 2 & 0 & 0 & 98 \\
Water + antagonist & 100 & 0 & 0 & 0 \\
$0.5 \%$ juice + antagonist & 98 & 2 & 0 & 0 \\
$5 \%$ juice + antagonist & 91 & 5 & 3 & 1 \\
\hline
\end{tabular}

a Germination rating scale: $1=$ no germination; $2=$ germ tube $<2 \times$ conidia size; 3 = germ tube 2 to $4 \times$ conidia size; $4=$ germ tube $>4 \times$ conidia size: 100 conidia per treatment were counted.

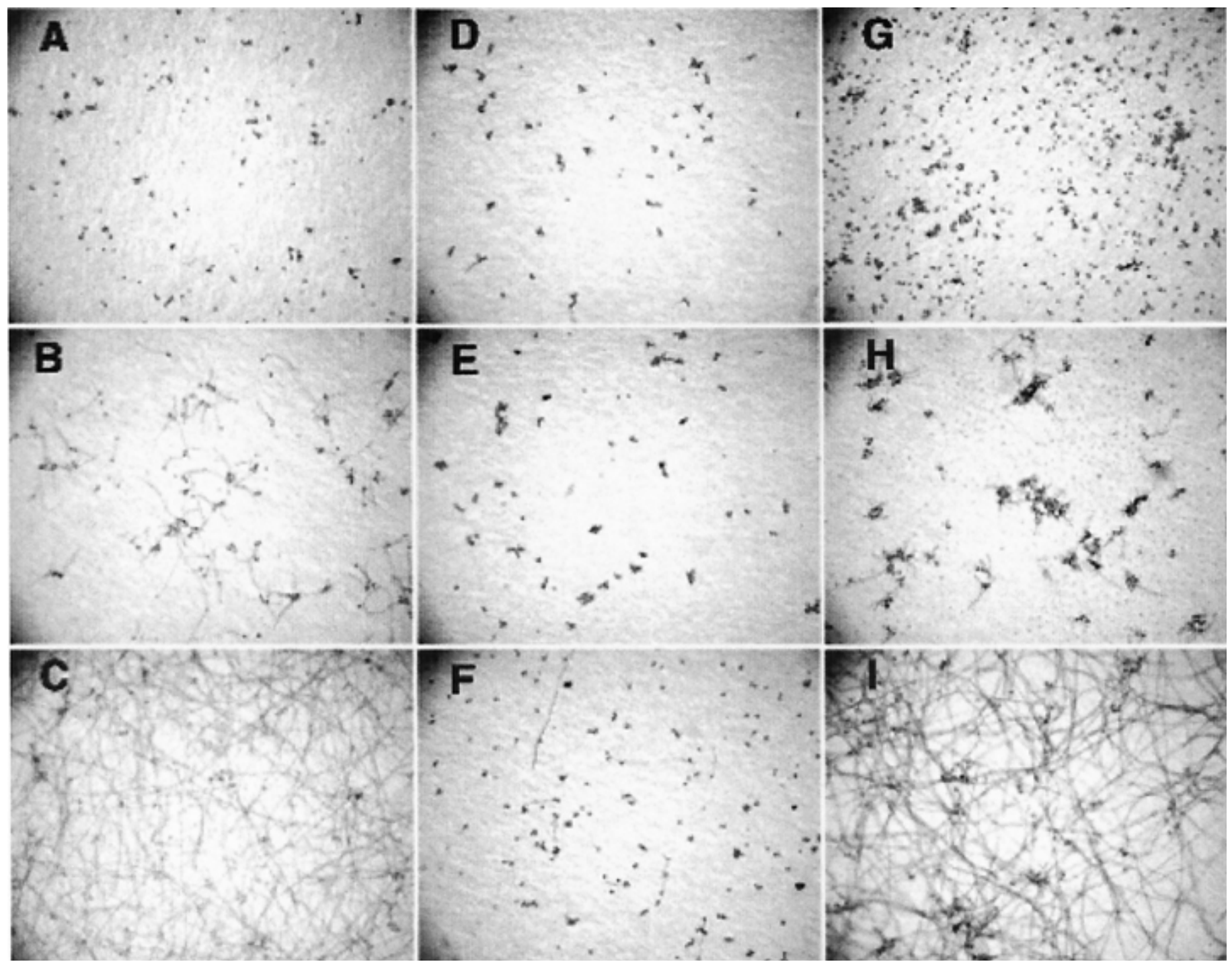

Fig. 2. Germination of the conidia on the membranes cut from the cylinders that were inserted for $24 \mathrm{~h}$ into wells containing A, water; B, apple juice at $0.5 \%$; C, apple juice at 5\%; D, water + antagonist ST1-A24; E, 0.5\% apple juice + antagonist ST1-A24; F, 5\% apple juice + antagonist ST1-A24; or treated as in D, E, and F, but placed in wells with G, water; H, $0.5 \%$ apple juice; I, and 5\% apple juice, respectively, for an additional $24 \mathrm{~h}$. 
$P$. expansum. Additional tests were conducted to confirm these results. The potential for the production of antifungal compounds by the antagonist was evaluated in dual culture tests on agar plates containing $20 \%$ water agar plus apple juice at $10,1,0.1$, or $0 \%$. In one set of plates the antagonist and the conidial suspension of the pathogen were streaked across each other on the dish. No inoculum was placed at the point of crossing to prevent carry over inoculum of one organism onto another. The inoculation with the antagonist and the pathogen was conducted simultaneously or the pathogen was applied 2 days after inoculation with the yeast. This delay allowed for diffusion of potential growth inhibitors from the antagonist into the medium. In the other set of agar plates, the pathogen and antagonist were streaked in parallel lines $\approx 3-\mathrm{cm}$ apart simultaneously. The plates were incubated at $22^{\circ} \mathrm{C}$ and evaluated for inhibition of pathogen growth over a period of 2 weeks. In a preliminary test, there was one plate per treatment, and the experiment was repeated with three plates per treatment.

\section{RESULTS}

Biocontrol tests on apples. A. pullulans isolate ST1-A24 was an effective antagonist in controlling blue mold decay on apples at room temperature and under cold storage conditions. At room

TABLE 2. Percent germination of Penicillium expansum conidia on PTFE membranes in cylinders exposed for $24 \mathrm{~h}$ at $26^{\circ} \mathrm{C}$ and reinserted to the new wells containing corresponding water or apple juice but without the antagonist for an additional $24 \mathrm{~h}$

\begin{tabular}{lrrrr}
\hline & \multicolumn{4}{c}{ Germination rating scale $^{\mathrm{a}}$} \\
\cline { 2 - 5 } Original treatment & 1 & 2 & 3 & \multicolumn{1}{c}{4} \\
\hline Water & 98 & 0 & 2 & 0 \\
0.5\% juice & 0 & 5 & 3 & 92 \\
$5 \%$ juice & 0 & 0 & 0 & 100 \\
Water + antagonist & 72 & 12 & 8 & 3 \\
0.5\% juice + antagonist & 56 & 18 & 15 & 11 \\
$5 \%$ juice + antagonist & 0 & 0 & 0 & 100 \\
\hline
\end{tabular}

${ }^{a}$ Germination rating scale: $1=$ no germination; $2=$ germ tube $<2 \times$ conidia size; $3=$ germ tube 2 to $4 \times$ conidia size; $4=$ germ tube $>4 \times$ conidia size: 100 conidia per treatment were counted. temperature the average lesion size was $11.3 \mathrm{~mm}$ for the control and $0 \mathrm{~mm}$ for the antagonist treatment. At $1^{\circ} \mathrm{C}$ the lesion size was 29.8 and $1.2 \mathrm{~mm}$ for control and antagonist treatments, respectively. The incidence of blue mold at room temperature was $94.4 \%$ for the control and $0 \%$ for the antagonist treatments, and at $1{ }^{\circ} \mathrm{C}$ it was $63.0 \%$ for the control and $3.0 \%$ for the antagonist treatments. This experiment verified that ST1-A24 was a good candidate to evaluate for interaction with $P$. expansum.

Interaction in plates with inserts. Conidia of $P$. expansum germinated at both concentrations of the apple juice within the first $24 \mathrm{~h}$ (Fig. 2B and C). At the higher concentration of the juice, more conidia germinated and germ tubes were strikingly longer (Fig. 2C; Table 1). Almost no germination occurred on conidia exposed to water (Fig. 2A; Table 1). The antagonist prevented germination of the conidia at $0.5 \%$ juice and greatly reduced germination in the higher juice concentration (Fig. 2E and F; Table1). Moving the cylinders containing ungerminated conidia from wells with the antagonist to wells without the antagonist resulted in germination of all conidia in 5\% juice and the majority of the conidia in $0.5 \%$ juice in the second $24-\mathrm{h}$ incubation period (Fig. 2H and I; Table 2).

Populations of the ST1-A24 antagonist increased from $4.35 \times$ $10^{6}$ to $5.12 \times 10^{6}$ and $5.50 \times 10^{6} \mathrm{CFU} / \mathrm{ml}$ in 0.5 and $5 \%$ juice, respectively, in the first $24 \mathrm{~h}$ of incubation. After blotting the bottom of the membranes and moving the inserts to other wells containing apple juice, no measurable growth of the antagonist occurred in the second $24 \mathrm{~h}$ incubation. Thus, no significant carryover of the antagonist occurred from the first to the second incubation well. Moving inserts from well to well may be useful in future experiments to further characterize antagonist-pathogen interactions.

Three major amino acids (aspartic acid, serine, and glutamic acid) were detected in the diluted apple juice (Fig. 3A). All three were depleted in the first $24 \mathrm{~h}$ of incubation with the yeast (Fig. 3B).

Interaction on agar plates. Filtrates from the wells containing the antagonist mixed with water or diluted apple juice did not inhibit $P$. expansum germination and growth in the agar diffusion test. Also, no inhibition of $P$. expansum growth occurred in either type of dual culture test on agar plates supplemented with apple juice.

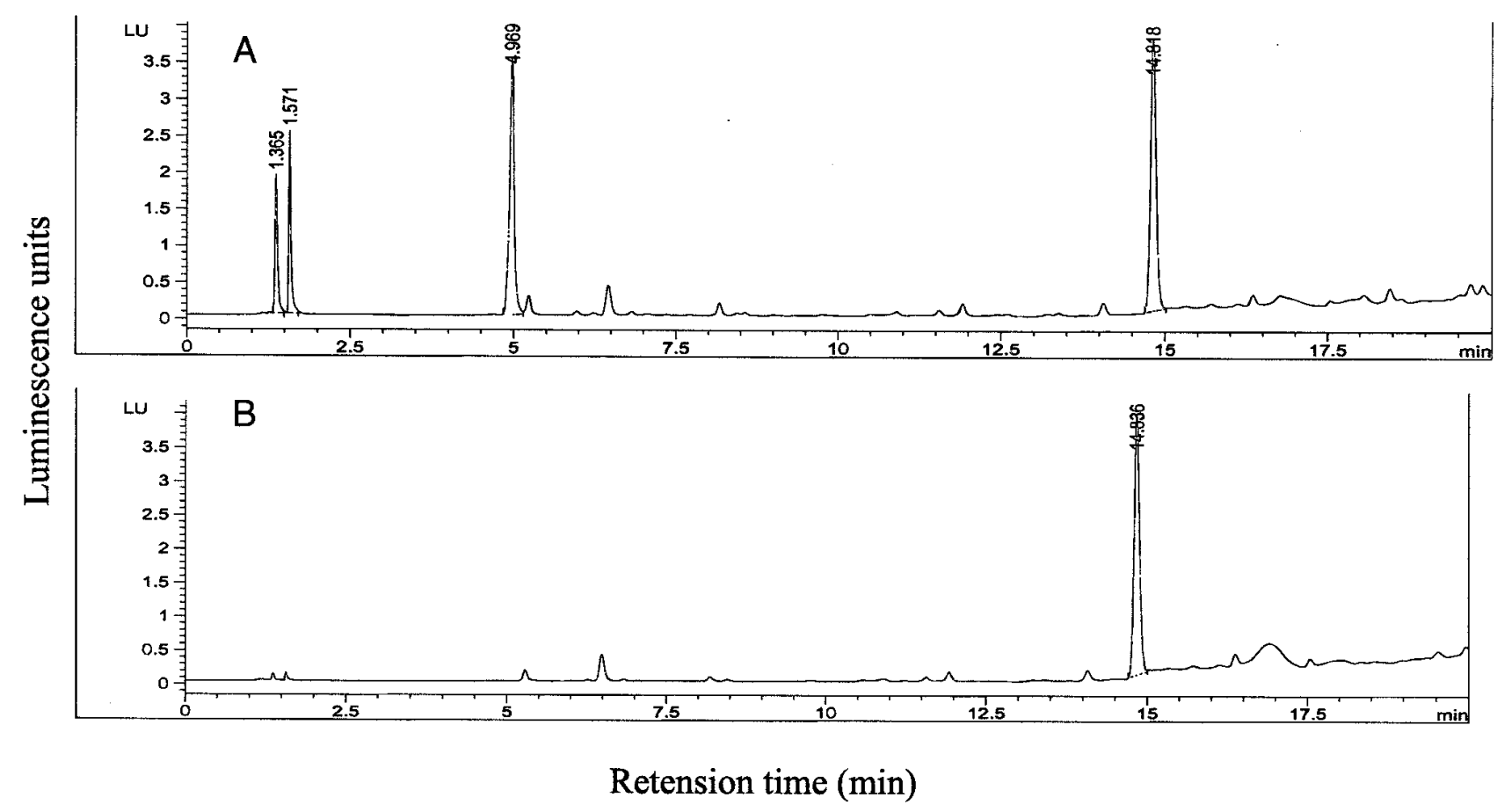

Fig. 3. Amino acid chromatographs of samples taken from wells containing A, 5\% apple juice and B, 5\% apple juice with antagonist ST1-A24 after 24 h incubation at $26^{\circ} \mathrm{C}$. The three major peaks from left to right represent aspartic acid (1.4 min), glutamic acid (1.6 min), and serine (4.9 min). The fourth peak (14.8 $\mathrm{min})$ represents a derivative. 


\section{DISCUSSION}

The postharvest system for biological control of fruit decay is unique in that both a pathogen and an antagonist come in direct contact at the infection court (fruit wound). Pome fruits after harvest are often treated with antioxidants that are suspended in water. This suspension is a major source of contamination with wound-invading pathogens such as $P$. expansum and Botrytis cinerea, but it can also serve as a delivery system for the antagonist. In addition, most of the postharvest handling of pome fruits is in water. In the past, inferences were often made that competition for nutrients and space plays an important role in many biocontrol systems on fruit but direct (and quantitative) evidence was lacking $(2,5,7,16,20,23-25)$. This, in large part, was due to the lack of appropriate methods to study the interactions. Separating competition for substrate from competition for space and ascribing significance to any one of them has been a formidable task. In this work we demonstrated that competition for a substrate can be studied in a simple in vitro system that simulates in vivo conditions.

The antagonist ST1-A24 effectively controlled fruit decay caused by $P$. expansum. It prevented conidia germination and depleted amino acids from apple juice in the well test in the first $24 \mathrm{~h}$ incubation. Although conidia did not germinate, they were viable because they germinated after being placed in diluted apple juice without the antagonist. Whether depletion of the amino acids alone was responsible for inhibition of conidia germination and biological control warrants further investigation. The advantage of this culture plate/insert method, however, lays in the ease of manipulation of the environment (e.g., amino acids can be reintroduced to wells and inserts can be moved to wells with different substrate) that allows the study of the effect of various factors on the pathogen in a nondestructive manner. This system can be useful in determining the efficacy of an antagonist in removing nutrients and relating this to a reduction in conidia germination and the ability to control fruit decay.

We developed a method where competition for nutrients and space are separated by a physical barrier between an antagonist and the pathogen. This method utilizes a substrate closely resembling that found under natural conditions. In this method the effect of the antagonist on the pathogen can be studied nondestructively. The pathogen conidia, after exposure to the suspension containing the antagonist, can be further tested for viability or the ability to cause fruit infection without interference from the antagonist. Also, as demonstrated in agar diffusion tests, this method can be used to study the role of antagonist metabolites, resulting from growth on a natural substrate, on pathogen conidia germination and growth. The well system can be used to determine a threshold and kinetics of nutrient depletion necessary for inhibition of germination of pathogens conidia by antagonists.

In addition to the study of nutritional interactions and the effect of antagonist metabolites, this method can be used to study the effects of a variety of treatments. Additives used under commercial conditions in packinghouses such as antioxidants or floatation salts can be tested to characterize their effects on antagonists, pathogens, and the resulting efficacy of biological control.

\section{LITERATURE CITED}

1. Barnett, J. A., Payne, R. W., and Yarrow, D. 1990. Yeast Characteristics and Identification. Cambridge University Press, Cambridge.

2. Clavente, V., Benuzzi, D., and de Tosetti, M. I. S. 1999. Antagonistic action of siderophores from Rhodotorula glutinis upon the postharvest pathogen Penicillium expansum. Int. Biodeterior. Biodegrad. 43:167-172.
3. Droby, S., Chalutz, E., Wilson, C. L., and Wisniewski, M. 1989. Characterization of the biocontrol activity of Debaryomyces hansenii in the control of Penicillium digitatum on grapefruit, Can. J. Microbiol. 35:794-800.

4. El-Ghaouth, A., Wilson, C. L., and Wisniewski, M. 1998. Ultrastructural and cytochemical aspects of the biological control of Botrytis cinerea by Candida saitoana in apple fruit. Phytopathology 88:282-291.

5. Filonow, A. B. 1998. Role of competition for sugars by yeasts in the biocontrol of gray mold of apple. Biocontrol Sci. Technol. 8:243-256.

6. Filonow, A. B. 1999. Yeast reduce the stimulatory effect of acetate esters from apple on the germination of Botrytis cinerea conidia. J. Chem. Ecol. 25:1555-1565.

7. Filonow, A. B., Vishniac, H. S., Anderson, J. A., and Janisiewicz, W. J. 1996. Biological control of Botrytis cinerea in apple by yeasts from various habitats and their putative mechanisms of antagonism. Biol. Control 7:212-220.

8. Grevesse, C, Jijakli, M. H., and Lepoivre, P. 1998. Study of exo- $\beta-1,3-$ glucanase activity production by yeast Pichia anomala in relation to its antagonistic properties against Botrytis cinerea on postharvest apples. Meded. Fac. Landbouwwet.-Rijksuniv. Gent. 63:1682-1685.

9. Janisiewicz, W. J. 1987. Postharvest biological control of blue mold on apples. Phytopathology 77:481-485.

10. Janisiewicz, W. J. 1988. Biological control of diseases of fruits. Pages 153-165 in: Biocontrol of Plant Diseases. Vol. 2. K. G. Mukerji and K. L. Garg, eds. CRC Press, Boca Raton, FL.

11. Janisiewicz, W. J. 1996. Ecological diversity, niche overlap, and coexistence of antagonists used in developing mixtures for biocontrol of postharvest diseases of apples. Phytopathology 86:473-479.

12. Janisiewicz, W. J. 1998. Biocontrol of postharvest diseases of temperate fruits. Pages 171-198 in: Plant-Microbe Interactions and Biological Control. G. J. Boland and L. D. Kuykendall, eds. Marcel Dekker Inc., New York.

13. Janisiewicz, W. J., and Bors, B. 1995. Development of a microbial community of bacterial and yeast antagonists to control wound-invading postharvest pathogens of fruits. Appl. Environ. Microbiol. 61:3261-3267.

14. Janisiewicz, W. J., Conway, W. S., Glenn, D. M., and Sams, C. E. 1998. Integrating biological control and calcium treatment for controlling postharvest decay of apples. HortScience 33:105-109.

15. Janisiewicz, W. J., and Jeffers, S. N. 1997. Efficacy of commercial formulation of two biofungicides for control of blue mold and gray mold of apples in cold storage. Crop Prot. 16:629-633.

16. Janisiewicz, W. J., and Marchi, A. 1992. Control of storage rots on various pear cultivars with a saprophytic strain of Pseudomonas syringae. Plant Dis. 76:555-560.

17. Janisiewicz, W. J., Peterson, D. L., and Bors, B. 1994. Control of storage decay of apples with Sporobolomyces roseus. Plant Dis. 78:466-470.

18. Janisiewicz, W. J., and Roitman, J. N. 1988. Biological control of blue mold and gray mold on apple and pear with Pseudomonas cepacia. Phytopathology 78:1697-1700.

19. Janisiewicz, W. J., and Tworkoski, T. 1998. Nutritional profiles enable selection of superior mixtures of antagonists to control blue mold of apples after harvest. Abstr. 2, 2.10.13 in: Int. Congr. Plant Pathol., 7th.

20. Jijakil, M. H., and Lepoivre, P. 1993. Biological control of postharvest Botrytis cinerea and Penicillium expansum on apples: Pages 106-110 in: Biological Control of Foliar and Post-Harvest Diseases. International Organization for Biological and Integrated Control on Noxious Animals and Plants/West Palaearctic Regional Section, Vol. 16.

21. Jijakli, M. H., and Lepoivre, P. 1998. Characterization of an exo- $\beta-1,3-$ glucanase produced by Pichia anomala strain k, antagonist of Botrytis cinerea on apples. Phytopathology 88:335-343.

22. Pusey, P. L. 1991. Antibiosis as mode of action in postharvest biological control. Pages 127-141 in: Workshop Proc. Biol. Control Postharv. Dis. Fruits Vegetables, U.S. Dep. Agric./Agric. Res. Sci. 92.

23. Roberts, R. G. 1990. Postharvest biological control of gray mold of apple by Cryptococcus laurentii. Phytopathology 80:526-530.

24. Wisniewski, M., Biles, C. L., Droby, S., McLaughlin, R., Wilson, C. L., and Chalutz, E. 1991. Mode of action of postharvest biocontrol yeast, Pichia guilliermondii: Characterization of attachment to Botrytis cinera. Physiol. Mol. Plant Pathol. 39:245-258.

25. Wisniewski, M., Wilson, C., and Hershberger, W. 1989. Characterization of inhibition of Rhizopus stolonifer germination and growth by Enterobacter cloacae. Can. J. Bot. 67:2317-2323. 